\title{
Milroy's disease and scrotal lymphoedema: pathological insight
}

\author{
Christi Butler, ${ }^{1}$ Charles Osterberg, ${ }^{1}$ Andrew Horvai, ${ }^{2}$ Benjamin Breyer $^{2}$
}

${ }^{1}$ Department of Urology, University of California San Francisco, San Francisco, California, USA

${ }^{2}$ Department of Pathology, University of California

San Francisco, San Francisco, California, USA

\section{Correspondence to} Dr Christi Butler, christi. butler@ucsf.edu

Accepted 12 April 2016
CrossMark

To cite: Butler $C$, Osterberg C, Horvai A, et al. BMJ Case Rep Published online: [please include Day Month Year] doi:10.1136/ bcr-2016-215396

\section{DESCRIPTION}

We highlight a case of Milroy's disease in a 28-year-old man. He originally presented with fleshy, exophytic coliform lesions that carpeted his scrotum and penile shaft (figure 1). His prior treatments included laser therapy and electrocautery, but the lesions recurred. Ultimately, he underwent a complex scrotal and phalloplasty, excision of coliform lesions and split thickness skin grafting. Postoperative findings are demonstrated in figure 2. Gross pathology revealed yellow-pink friable coliform excrescences (figure 3). H\&E stained microscopic sections showed papillary outgrowths of dermis with overlying epidermal hyperplasia and

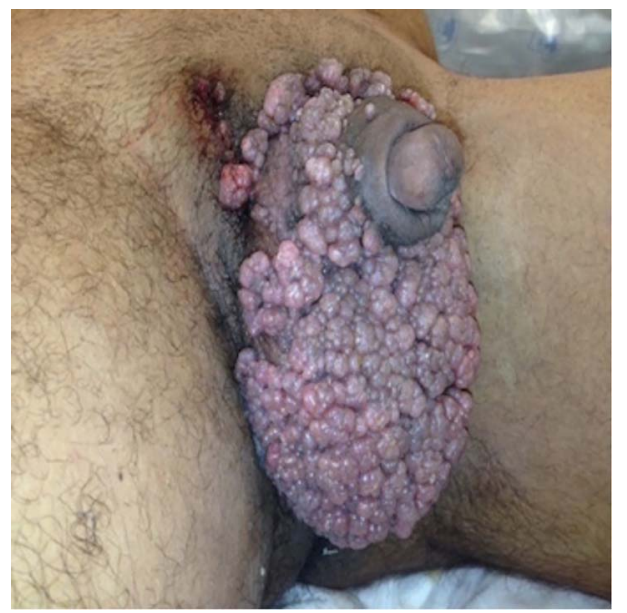

Figure 1 Presentation of diffuse coliform lesions throughout genitalia.

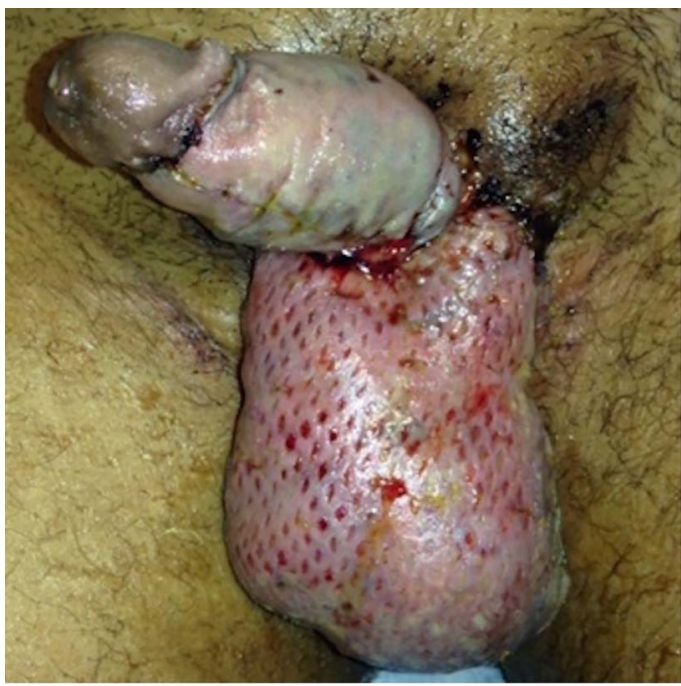

Figure 2 Several days postoperation after dressing removal. hyperkeratosis. The deeper dermis was oedematous and fibrotic with a dense chronic inflammatory infiltrate and lymphangiectasia (figures 4-7). The histological findings were consistent with chronic lymphatic obstruction.

Three years later, the patient developed mild, asymptomatic penile oedema and a small, solitary coliform lesion at the base of his penis, over the graft site and right groin (figure 8). A shave biopsy

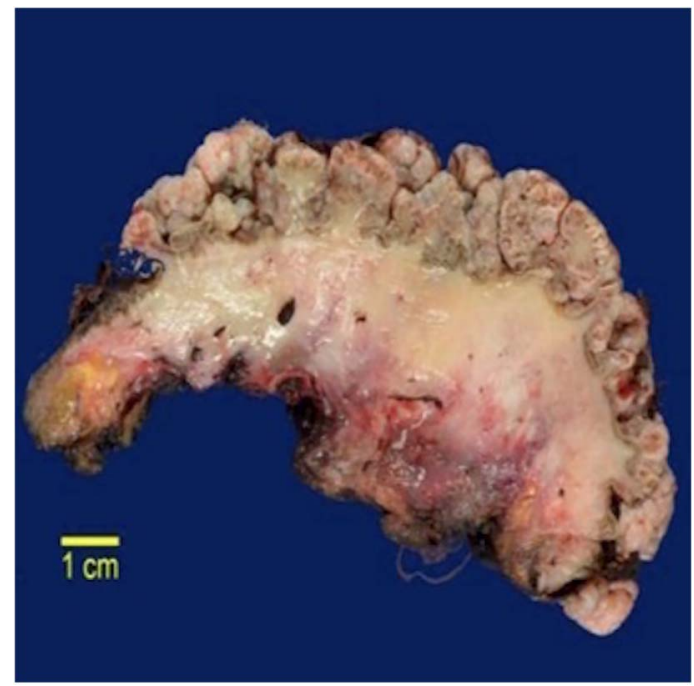

Figure 3 Gross specimen: cross section of excision specimen consisting of multinodular, coliform excrescences of epidermis and oedematous dermis ranging from $2 \mathrm{~mm}$ to $1.5 \mathrm{~cm}$ in diameter. The deep dermis was diffusely oedematous and soft.

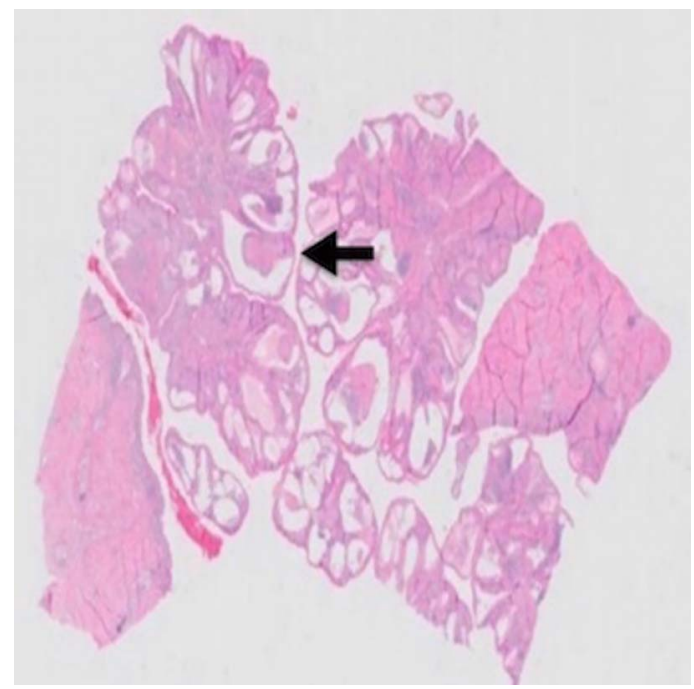

Figure 4 H\&E microscopic sections demonstrating papillary outgrowths of epidermis. 


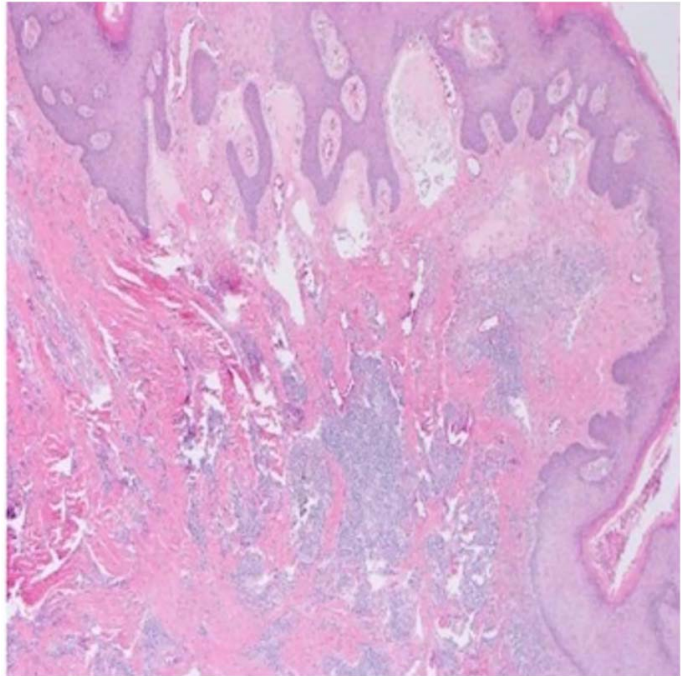

Figure 5 H\&E deep dermis contained fibrosis, a dense chronic inflammatory infiltrate and pigment incontinence.

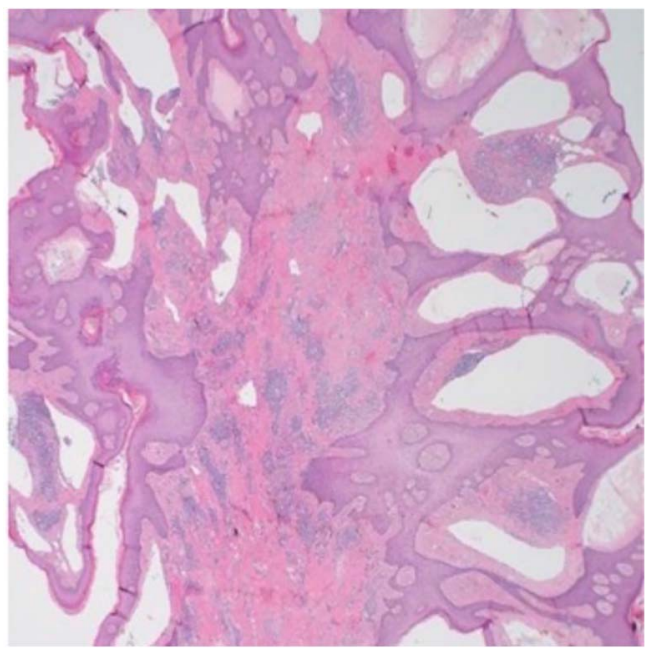

Figure 6 H\&E dilated lymphatics beneath hyperkeratotic epidermis.

was performed and demonstrated lymphangiectasia (not shown). Overall, the patient reported excellent sexual function and was very pleased with the results of surgery.

Milroy's disease is a rare genetic disorder that impairs normal lymphatic drainage. ${ }^{1}$ It can affect various parts of the body, specifically dependent areas such as the lower extremities and genitals. Management options include non-operative and operative measures. However, little is known about the pathological features of Milroy's disease and its long-term outcomes.

This case highlights several learning points: (1) Histological changes are consistent with chronic lymphatic obstruction. (2) Milroy's disease is prone to local recurrence. (3) Excision of the dermal layer has been associated with good cosmetic outcome.

Chronic lymphoedema is characterised, microscopically, by interstitial fluid accumulation, dilation of lymphatic outflow tracts and fibrosis. ${ }^{1} 2$ Our histopathological findings support that the pathogenesis of Milroy's disease is based on chronic lymphatic obstruction. We also demonstrate that Milroy's disease is a chronic and recalcitrant condition. It may recur at the site of previous excision and grafting. Similar findings have

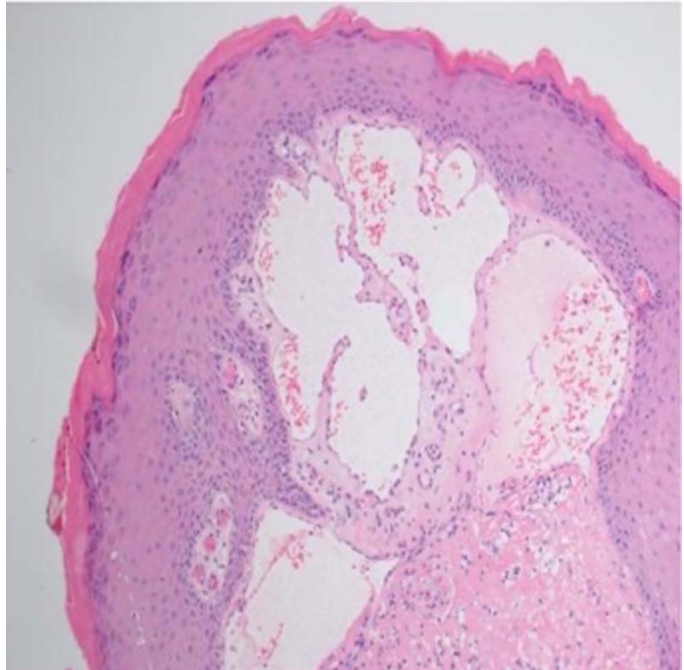

Figure 7 H\&E dilated lymphatics beneath hyperkeratotic epidermis.

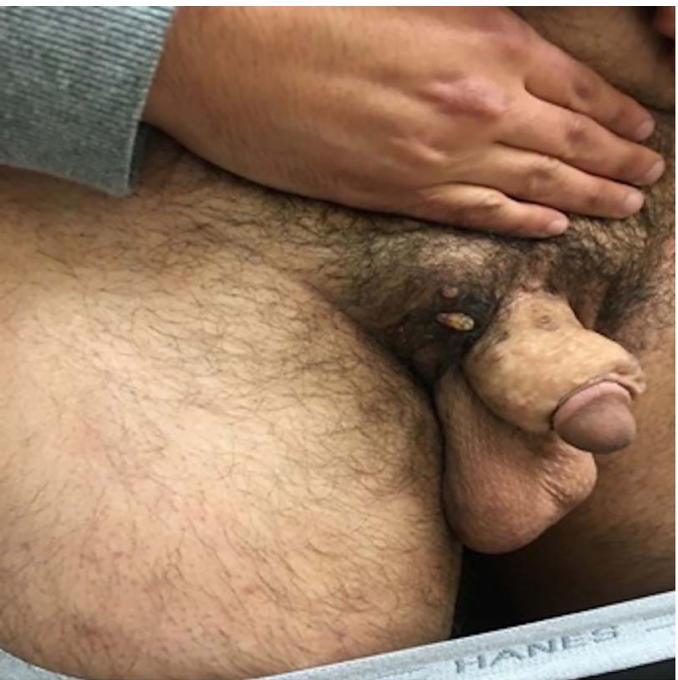

Figure 8 Three-year follow-up visit with groin and penile lesion.

been reported with other forms of chronic lymphoedema. Machol et $a l^{3}$ noted that patients with massive localised lymphoedema of the scrotum, had a $50 \%$ chance of recurrence after treatment. These recurrences ranged from simple fluid reaccumulation to redemonstration of dermatological pathology.

It remains unclear whether complete excision of the dermal layer is crucial for management of Milroy's disease, but the literature examining the histopathology of excised genital skin with chronic lymphoedema is limited. ${ }^{2}{ }^{3}$ We demonstrate, with histopathology, the extensive involvement of superficial dermal lymphatics and full-thickness dermal fibrosis with only a

\section{Learning points}

- Histological changes are consistent with chronic lymphatic obstruction.

- Milroy's disease is prone to local recurrence.

- Excision of the dermal layer has been associated with good cosmetic outcome. 
limited, focal recurrence after complete excision of all involved dermis. Taken together, the above findings suggest that complete removal of the dermal layer may result in a more successful outcome for these patients than a superficial excision.

Contributors $C B$ and $C O$ contributed in editing the manuscript; $A H$ was responsible for pathology expert review; BB was involved in final editing, final analysis, idea conception and expert review.

Competing interests None declared.

Patient consent Obtained.
Provenance and peer review Not commissioned; externally peer reviewed.

\section{REFERENCES}

1 'Milroy Disease.' Genetics Home Reference [Internet]. April 2013 [cited 30 Jan 2016]. http://ghr.nlm.nih.gov/condition/milroy-disease

2 Plaza JA, Requena L, Kazakov DV, et al. Verrucous localized lymphedema of genita areas: clinicopathologic report of 18 cases of this rare entity. J Am Acad Dermatol 2014:71:320-6.

3 Machol JA IV, Langenstroer P, Sanger JR. Surgical reduction of scrotal massive localized lymphedema (MLL) in obesity. J Plast Reconstr Aesthet Surg 2014:67:1719-25

Copyright 2016 BMJ Publishing Group. All rights reserved. For permission to reuse any of this content visit http://group.bmj.com/group/rights-licensing/permissions.

BMJ Case Report Fellows may re-use this article for personal use and teaching without any further permission.

Become a Fellow of BMJ Case Reports today and you can

- Submit as many cases as you like

- Enjoy fast sympathetic peer review and rapid publication of accepted articles

- Access all the published articles

- Re-use any of the published material for personal use and teaching without further permission

For information on Institutional Fellowships contact consortiasales@bmjgroup.com

Visit casereports.bmj.com for more articles like this and to become a Fellow 